\title{
Financial Strain and Loss of Psychosocial Benefits of Work Mediate the Relationship between Sickness Absence and Depression among People with Work Disability
}

\author{
Julie P. Sutton and Debra A. Dunstan \\ School of Behavioural, Cognitive and Social Sciences, University of New England, Australia
}

\begin{abstract}
$\mathrm{T}$ his study examined the relationship between sickness absence from work, loss of the benefits of employment, and depression in injured workers. A sample of 112 clients of Australian occupational rehabilitation service providers were the participants: $($ men $=56$; women $=56$; mean age $=45.25$ years, $S D=$ 10.34). Each had a chronic ( $>3$ months) work-related musculoskeletal injury; $49 \%$ were sickness absent $(n=55)$ and $51 \%$ were partially fit and performing modified duties $(n=57)$. All completed self-report measures of the nature and duration of sickness absence, access to the benefits of employment, and severity of depression symptoms. Bootstrapping mediational analyses found that the relationship between duration of sickness absence and depression was fully mediated by financial strain and psychosocial benefits of employment. Financial strain was also the strongest predictor of depression in circumstances of sickness absence, but collective purpose was the strongest predictor when modified duties were being performed. These findings support injury management policies aimed at minimising injured workers' social and physical separation from the workplace and assisting sickness absent workers to maintain connections with their work team.
\end{abstract}

Keywords: workplace injury, depression, sickness absence, mediators, financial strain, loss of social contact

The prevalence of depression is significantly higher in sickness absent physically injured workers than in the general population (Dersh, Gatchel, Polatin, \& Mayer, 2002). This difference begins to emerge as early as one month after workplace separation (Bültmann et al., 2007) and, in Australia, by 12 months shows a prevalence rate difference of $55.4 \%$ compared to $4.1 \%$ in the general population (Australian Bureau of Statistics, 2007). Studies examining this finding reveal that work separation is associated with the emergence of psychological distress (Cohen, Nicholas, \& Blanch, 2000), and can result in depression and chronic work disability (Sullivan,

Address correspondence to: Debra A. Dunstan, Discipline of Psychology, School of Behavioural, Cognitive and Social Sciences, University of New England, Armidale 2351, Australia. E-mail: ddunstan@une.edu.au 
Adams, Tripp, \& Stanish, 2008). Given the substantial personal and socioeconomic costs of this outcome (Australian Safety and Compensation Council, 2009; Health \& Safety Executive, 2010; World Health Organization, 2003), an understanding of the mechanisms mediating the relationship between sickness absence and depression may be useful for informing prevention or intervention strategies. Using a sample of injured workers, the aim of this study was to identify mediating variables in the relationships between sickness absence and depression.

\section{Work and mental well-being}

Medical, political and social authorities are unanimous in their assertion that work is generally good for people because it facilitates social and economic inclusion (Australian Government, 2008) and affords a wide range of health benefits (AFOEM \& RACP, 2011). The converse is also true; unemployment is damaging for working-aged adults (Dunstan, 2009). Compared to the employed, unemployed people have poorer physical and mental health. Longitudinal research has shown that employment is the moderating factor in the work-health relationship (Winefield et al., 2002) and that improvements in well-being follow re-employment (Fryer, 2002; McKee-Ryan, Song, Wanberg, \& Kinicki, 2005).

To explain the effects of unemployment on mental health, two main theories have emerged: Jahoda's (1982) 'latent deprivation model' and Fryer's (1995) 'agency restriction model'. Jahoda argues that in addition to financial rewards (the manifest benefit of employment), employment also provides psychosocial (or latent) benefits in the form of time structure, social contact, social status, engagement in meaningful activity and shared collective purpose. The theory posits that when an unemployed person is deprived of these benefits, their mental well-being is likely to decline (Jahoda, 1982).

Empirical research has provided support for the latent deprivation model (Jackson, 1999) showing that unemployment is associated with lower levels of time structure (Wanberg, Griffiths, \& Gavin, 1997), less engagement in social activities (Underlid, 1996), more frequent participation in solitary activities (Waters \& Moore, 2002), lower social status (Batinic, Selenko, Stiglbauer, \& Paul, 2010) and less involvement in activities with a collective purpose (Creed \& Macintyre, 2001). Furthermore, the loss of these latent benefits has been found to account for $30 \%$ of the explained variance in the depressive affect of the unemployed (Waters \& Moore, 2002). However, findings in regard to the relative importance of individual latent benefits have been equivocal.

In addition to the above uncertainties, Jahoda's model has been challenged by Fryer $(1986,1995)$ and others (e.g., Creed \& Klisch, 2005; Fryer \& McKenna, 1987; Whelan, 1992) who contend that financial strain is the greatest challenge to the mental well-being of unemployed people. In his agency restriction model, Fryer identifies poverty as the 'psychologically corrosive' $(1995$, p. 270) feature of unemployment because it limits a person's capacity to access wants and needs, and impairs hope for a meaningful future. A number of studies have shown support for this model (Price, Choi, \& Vinokur, 2002; Szanton, Thorpe, \& Whitfield, 2010) but others indicate that both agency restriction and the latent deprivation model have validity. For instance, Creed and McIntyre (2001) examined the relative contributions of financial strain and each of the five latent benefits of work (time structure, activity, collective purpose, 
social contact and status) in predicting psychological well-being within a sample of 248 unemployed (but not disabled) people.

Using a standard multiple regression analysis, Creed and McIntyre (2001) found that the latent and manifest benefits of employment together accounted for $52 \%$ of variance in psychological well-being. Financial strain made the largest unique contribution, independently accounting for $16.81 \%$ of the variance. However, the latent benefits of employment also contributed significantly: Status independently accounted for $7.84 \%$ of variance, time structure uniquely contributed $5.30 \%$, and collective purpose uniquely accounted for $1.96 \%$ of total variance in psychological well-being. Activity and social contact, while not making significant unique contributions to the prediction of psychological well-being, did contribute to overall variability. In a subsequent study, Creed and Klisch (2005) found that even though the effect of Jahoda's latent variables became non-significant after controlling for financial strain and future outlook, each showed a significant bivariate correlation with psychological distress.

Based on the existing empirical literature, it seems reasonable to conclude that financial strain is the predominant mediator in the relationship between unemployment and psychological distress in the general population. However, the impact of this manifest benefit - compared to latent benefits — on the psychological outcomes of people separated from the workplace due to injury is not known. Given that injured workers are subject to a unique set of financial, social and regulatory pressures (Beardwood, Kirsh, \& Clark, 2005) — which in Australia includes the entitlement to full pre-injury wages for at least six months post-injury, and make-up pay until retirement if performing modified duties (WorkCover Authority of NSW, 2011) the results may be different in this population.

\section{Depression and duration of work absence following injury}

A substantial body of literature attests to the high risk of physically injured workers developing depression and a reduced likelihood of return to work as the duration of sickness absence increases (Stice \& Dik, 2009). This risk rises exponentially after three months off work (Frank et al., 1998). After six months off, the likelihood of work resumption is only $50 \%$, and by one year the return to work rate is around $15 \%$. After two years this rate falls to 2\% (Gamborg, Elliott, \& Curtis, 1992; Watson, 2001).

It has been proposed that depression and chronic sickness absence are caused by physical injury factors (including pain), but such causal relationships have not been conclusively demonstrated (Fishbain, Cutler, Rosomoff, \& Rosomoff, 1997). Indeed, countering this view is the finding that the diagnoses of physically injured people who fail to return to work are not different to those who do (Cohen et al., 2000). Additionally, other studies (e.g., Baril, Clarke, Friesen, Stock, \& Cole, 2003; Gamborg et al., 1992) confirm that sickness absent injured workers get caught up in a vicious cycle of physical and psychosocial influences that impair their health and well-being beyond that attributable to their injury. In recognition of this phenomenon, workers compensation authorities around the world nowadays prescribe injury management practices that promote early work resumption (New York State Workers Compensation Board, 2009; WorkCover Authority of NSW, 2010a; Workplace Safety and Insurance Board, 2011) to reduce injured workers' exposure to psychosocial risk factors for chronic pain, distress and disability (Pincus, Burton, Vogel, \& Field, 2002). 


\section{Workers compensation procedures following injury}

Informed by empirical and epidemiological data, and motivated by cost containment, workers' compensation authorities in Australia and other Western nations (e.g., Canada, USA, Great Britain and many European countries) seek to minimise injured workers' sickness absence by requiring employers and injured workers to engage in a policy of 'early contact' and 'early return to work' (MacEachen, Ferrier, Kosny, \& Chambers, 2007). Early contact involves maintaining communication with a sick-listed employee; early return to work allows for the performance of part-time or full-time modified duties, at the workplace, during a period of partial fitness prior to full recovery (Franche et al., 2005; WorkCover Authority of NSW, 2010a; WorkCover Authority of NSW, 2011). Although not stated in any literature of which the authors are aware, these combined strategies potentially maintain the manifest and latent benefits of work by sustaining wages (at or close to pre-injury levels) and keeping the employee socially connected to peers and workplace social structures. These strategies have been shown to be effective in supporting the timely return to full duties of the majority of injured workers (Franche et al., 2005; Kuoppala \& Lamminpää, 2008), however, managers and co-workers sometimes feel awkward about engaging in 'early contact' (Tjulin, MacEachen, \& Ekberg, 2011), and modified duties are not always available to support an 'early return' (Nicholas, 2002). However, given this overarching procedural framework, and until income is significantly reduced (in Australia this is when total incapacity persists beyond six months), it is likely that the loss of the latent benefits of work will have more influence than financial strain on the presence of depression in partially fit injured workers. In contrast, when sickness absence persists and wage replacement benefits are reduced, financial strain may be the greatest influence on psychological distress.

\section{Goal of this Study}

In view of the known association between sickness absence and depression in injured workers, the goal of this study was to identify the variables mediating this relationship. The aim of the study was to assess the relative contribution to depression, of financial strain and the five latent psychosocial benefits of employment, in a sample of Australian injured workers. We hypothesised that symptoms of depression would increase as sickness absence increased and that financial strain, plus the loss of latent benefits of work, would mediate the relationship between sickness absence and depression. In the condition of prolonged sickness absence, we hypothesised that financial strain would be the strongest predictor of depression, however, when modified duties were being performed, we hypothesised that loss of latent benefits of work (such as time structure, social contact, status, activity and shared goals) would be the stronger predictor.

\section{Method}

\section{Participants and setting}

The sample comprised 112 participants who were receiving occupational rehabilitation services following a workplace injury. The total sample included 56 men and 
56 women (mean age $=45.25$ years, $S D=10.34$, range 23.08 to 65.68 years). All participants had a musculoskeletal disorder - the most common workplace injury in Australia (WorkCover Authority of NSW, 2010b) - and had been work injured for at least 12 weeks (mean time since injury $=38.18$ months, $S D=46.02$, range 3.09 to 277.95 months), meaning they were at risk of secondary psychological distress (Cohen et al., 2000). The mean duration of sickness absence (from the last day of work to date of survey) was 8.46 months, $(S D=14.73$ months $)$ and ranged from 0 months (for those currently working) to 68.03 months. Fifty-seven participants were still at work (performing modified duties on a full-time or reduced hours basis), and 55 were sickness absent. Information regarding current and pre-injury income was not available for the current study, but as $71 \%$ of the sickness absent group had been off work for more than six months, it can be assumed that their income was significantly less than their pre-injury earnings.

\section{Measures}

Participants completed two self-report measures: The Self-Rating Depression Scale (SDS; Zung, 1965) and The Latent and Manifest Benefits of Employment (LAMB) scale (Muller, Creed, Waters, \& Machin, 2005), described below. They also responded to items asking the date on which they were injured, the date they last worked, and several questions on their personal demographics.

The Self-Rating Depression Scale (SDS; Zung, 1965) is a 20-item self-report measure of the key affective, cognitive, behavioural and physiological symptoms of depression. Participants respond to a series of statements (e.g. I feel down-hearted and blue) by indicating to what degree the statement has applied in the past week: none or a little of the time; some of the time; a good part of the time; or, most of the time. Scores range from 20 to 80 with scores in the 50 s indicating mild depression, 60 to 69 reflecting moderate depression and scores of over 70 indicating severe depression.

The SDS has excellent internal consistency with reported split-half reliability ranging from 0.79 (de Jonghe \& Baneke, 1989) to 0.94 (Gabrys \& Peters, 1985), and Cronbach alpha coefficients of 0.82 (de Jonghe $\&$ Baneke, 1989), 0.88 to 0.93 (Gabrys \& Peters, 1985), and 0.86 to 0.90 (Schaeffer et al., 1985). In the current study, the Cronbach alpha coefficient was 0.90 . The scale correlates highly with the Beck Depression Inventory (Beck, Ward, Mendelson, Mock, \& Erraugh, 1961), with reported zero order correlations of 0.76 and 0.81 (Schaeffer et al., 1985). High correlations have also been reported between the SDS and the Hamilton Rating Scale for Depression (Hamilton, 1960), $r=0.8$ (Biggs, Wylie, \& Ziegler, 1978), the Depression Scale of the Minnesota Multiphasic Personality Inventory (MMPI; Hathaway \& McKinley, 1942), $r=0.61$ and 0.73 (Schaeffer et al., 1985), and the MMPI-2 Depression Scale (Butcher, Dahlstrom, Graham, Tellegen, \& Kraemmer, 1989), $r=0.77$ (Thurber, Snow \& Honts, 2002). The scale has been shown to effectively discriminate between depressed and non-depressed samples (Biggs et al., 1978; de Jonghe \& Baneke, 1989; Gabrys \& Peters, 1985; Schaeffer et al., 1985; Thurber et al., 2002), and to adequately distinguish between mild, moderate and severe depressive symptoms (Biggs et al., 1978). 
The Latent and Manifest Benefits of Employment (LAMB) scale (Muller et al., 2005) is a 36-item self-report measure comprising six independent subscales of six items each. Participants indicate their agreement to a series of bipolar statements in a 7point response format. Each subscale measures one of the six benefits of employment: the time structure subscale contains statements regarding the structured and purposeful use of time, e.g., I often have a lot of time on my hands / I rarely have a lot of time on my hands; the social contact subscale relates to opportunities for social interaction and access to social support, e.g., I rarely have a lot of opportunities to mix with people I I usually have a lot of opportunities to mix with people; the collective purpose subscale reflects a sense of connection with the wider community and of working with others toward shared goals, e.g., I rarely feel that I make a meaningful contribution to society / I often feel that I make a meaningful contribution to society; the enforced activity subscale taps the degree to which a participant engages in required activities in order to fulfill role expectations, e.g., I usually need others to push me to do things / I rarely need others to push me to do things; items in the status subscale tap into a person's social identity and sense having a meaningful role within society, e.g., I am rarely valued by the people around me / I am often valued by the people around me; financial strain reflects the degree to which financial resources limit capacity for non-essential spending, e.g., My income usually allows me to do the things I want / My income rarely allows me to do the things I want. Scores for each subscale range from 6 to 42 , with higher scores indicating more access to the particular benefit. Scores on the financial strain subscale are reversed so that high scores indicate less financial strain.

Construct validity for each of the LAMB subscales was established via confirmatory factor analysis (Muller et al., 2005). Muller and colleagues reported criterion and divergent validity for the subscales based on appropriate association with, and independence from, measures of negative affect (General Health Questionnaire; Goldberg, 1972), neuroticism (Eysenk Personality Questionnaire - Revised; Eysenk \& Eysenk, 1996), and demographic variables. Muller and colleagues (2005) reported acceptable to excellent subscale reliability: Cronbach alpha coefficients for the subscales were 0.74 (time structure), 0.92 (social contact), 0.91 (collective purpose), 0.89 (enforced activity), 0.91 (status), and 0.93 (financial strain). In the current study, the Cronbach alpha coefficients were 0.93 (time structure), 0.95 (social contact), 0.96 (collective purpose), 0.89 (enforced activity), 0.91 (status), and 0.97 (financial strain).

\section{Procedure}

Subsequent to approval from the University of New England Human Research Ethics Committee (HE10/009), accredited rehabilitation services in NSW were contacted by email and telephone and invited to take part in this and four related studies (not reported on here). Service providers who declined the invitation, or from whom we received no response, were not contacted again. Participating providers in northern NSW were visited personally by the researchers, while those in other areas received instructions and study materials by post and email. Staff at participating offices were asked to invite eligible clients to participate. Clients who had sustained a work-related musculoskeletal injury more than 12 weeks prior to the study, and who remained either totally unfit or partially fit for work (i.e., either off work entirely or at work performing 
modified duties on a part-time or full-time basis) were eligible to participate. After providing informed consent, respondents completed a battery of scales, either online or in pencil and paper format, and were provided with a $\$ 10$ gift voucher on completion. The degree to which the final sample is representative of the wider population of injured workers is unknown: Not all rehabilitation providers chose to take part in the study; also, as potential participants were initially contacted by their rehabilitation providers rather than the researchers, it is not known what percentage of eligible clients declined the invitation to participate.

\section{Data Analysis}

Pearson product-moment correlations were generated for the associations between duration of sickness absence and depression (SDS score), between the duration of sickness absence and LAMB subscale scores, and between LAMB scores and depression. Multiple mediator bootstrapping analyses (Preacher \& Hayes, 2008a) were conducted to determine any mediating effects of the latent and manifest benefits of employment on the relationship between duration of sickness absence and depression.

The bootstrapping approach to mediation (Shrout \& Bolger, 2002) has been shown to offer superior statistical power and reduced type-I error rates when compared to the causal steps and normal theory approaches to mediation, particularly when applied (as in the current study) to small to medium sized samples or to non-normally distributed data (Mallinckrodt, Abraham, Wei, \& Russell, 2006). Bootstrapping is a method of random resampling with replacement, such that each case may be selected once, more than once, or not at all during each resampling event until $n$ cases have been selected. The procedure is repeated multiple times (1,000 times in the current study) in order to simulate multiple random samples from the wider population. Effect coefficients are calculated for each sampling event. The resulting point estimate is the mean of the coefficients recorded over the multiple samples. The $95 \%$ confidence interval is achieved by ordinal ranking of the multiple coefficients, with the lower and upper bounds of the confidence interval defined as the 2.5th and 97.5th percentiles. An effect is assumed to be significant at $p<0.05$ if the $95 \%$ confidence interval does not include zero.

The multiple mediator bootstrapping analysis (Preacher \& Hayes, 2008a) enables significance testing of the combined mediating effect of all proposed mediators (total indirect effect) and, importantly, of the unique mediating effect of each proposed mediator, after controlling for the mediating effects of other variables (specific indirect effects). It also enables comparison of each specific indirect effect with every other specific indirect effect (contrasts) to determine whether the mediating effect of any single mediator is significantly greater than that of any other potential mediator. Computational syntax developed by Preacher and Hayes (2008b) generates output describing the point estimate and 95\% confidence interval for each specific indirect effect and for each contrast as well as effect sizes and significance estimates for Sobel's (1982, 1986) product-of-coefficients test.

Pearson correlation and multiple regression analyses were conducted post-hoc to separately assess the relationships between LAMB scores and depression for the sickness absent and partial fitness/modified duties groups. 


\section{TABLE 1}

Percentage of each group reporting depressive symptoms in the sub-clinical, mild, moderate, and severe ranges

\begin{tabular}{lcc}
\hline SDS score & At work- modified duties & Sickness absent \\
\hline$<50$ (sub-clinical) & 75.4 & 52.7 \\
$50-59$ (mild) & 22.8 & 38.2 \\
$60-69$ (moderate) & 1.8 & 9.5 \\
$70-80$ (severe) & nil & nil \\
\hline
\end{tabular}

\section{Results}

\section{Prevalence and severity of depression}

The nature and severity of self-reported depression symptoms were measured using the SDS (Zung, 1965). Forty-two participants ( $n=42 ; 36.2 \%$ of the sample) reported current symptoms of depression in the clinical range (SDS scores of 50 or higher). The duration of sickness absence and SDS scores showed a significant, positive, moderate correlation $(r=0.39, p<.001)$ indicating that SDS scores tended to increase as the length of separation from the workplace increased.

The relationship between work participation status - at work performing modified duties or sickness absent - and the SDS scores was examined using an independent samples t-test. There was a significant difference in mean SDS scores for those participants performing modified duties $(M=41.32, S D=10.75)$ and those who were sickness absent, $(M=47.11, S D=11.00), t(110)=-2.82, p=0.006$; this difference (mean difference $=5.79,95 \%$ CI: 1.72 to 11.00 ) equating to a moderate effect size $\left(\eta^{2}=0.07\right)$.

The incidence of depression was higher in the sickness absent group $(n=27 ; 47.3 \%$ of this group) than in the modified duties group ( $n=14 ; 24.6 \%$ of this group). Table 1 shows the percentage of each group reporting sub-clinical, mild, moderate and severe depressive symptoms. A chi-square test for independence (with Yates Continuity Correction) was conducted to assess the relationship between work participation and clinical range depression (SDS scores below 50 versus scores of 50 or above). A significant association was found, $\chi^{2}(1, n=112)=5.34, p=0.02$, with a small to medium effect size ( $p h i=0.24, p=0.01$ ), indicating significantly higher rates of clinical range depressive symptoms in the sickness absent group.

A second chi-square test for independence was conducted to assess the relationship between work participation and severity of clinical range depression: mild (50-59), moderate (60-69), or severe (above 70). The sickness absent group had a higher incidence of mild and moderate depression than did the working group (see Table 1), $\chi^{2}(2, n=112)=7.24, p=0.03$, with a medium effect size (Cramer's $V=0.25, p=$ $0.03)$. No participant in either group reported severe depressive symptoms.

\section{Latent and manifest benefits of work}

The possible mediating effects of the latent and manifest benefits of employment (as measured by the LAMB subscales) on the relationship between duration of sickness absence and depression was assessed in a number of steps: first, LAMB subscale 


\section{TABLE 2}

Bivariate correlations between LAMB scores and SDS

\begin{tabular}{lc}
\hline LAMB Subscale & Correlation with SDS $(r)$ \\
\hline Time Structure & $-.49 * * *$ \\
Social Contact & $-.50 * * *$ \\
Collective Purpose & $-.60 * * *$ \\
Enforced Activity & $-.54 * * *$ \\
Status & $-.48 * * *$ \\
Financial Strain & $-.67 * * *$ \\
\hline
\end{tabular}

$* * * p<.001$

correlations with SDS scores and duration of sickness absence were calculated; then mediation analysis was conducted using the LAMB subscales that showed significant bivariate correlations with both duration of sickness absence and SDS.

\section{Relationship to depression}

Pearson product-moment correlation analyses were conducted to assess the strength of association between LAMB subscales (time structure, social contact, collective purpose, enforced activity, status, and financial strain) and SDS scores (see Table 2). Significant negative correlations were demonstrated between each of the six LAMB subscales and SDS scores (time structure $\times$ SDS, $r=-0.49$; social contact $\times$ SDS, $r=$ -0.50 ; collective purpose $\times$ SDS, $r=-0.60$; enforced activity $\times$ SDS, $r=-0.54$; status $\times$ SDS, $r=-0.67$ ), and, as the LAMB scores increased (indicating greater levels of work-related benefits), severity of depressive symptoms decreased (as indicated by lower SDS scores). This suggests that reduced access to the benefits of employment, as measured by the LAMB subscales, is associated with increased depression.

\section{Relationship to Sickness Absence}

Pearson product-moment correlation analyses revealed significant, small to medium negative correlations between duration of sickness absence and four of the six LAMB subscales: time structure, social contact, collective purpose and financial strain Scores on the four LAMB subscales tended to decrease as the duration of sickness absence increased (see Table 3), suggesting that longer separation from the workplace is associated with reduced access to these four benefits of work. The four significantly correlated subscales (financial strain, time structure, collective purpose and social contact) were retained for use in the mediation analysis.

\section{Mediation analyses}

A multiple mediation bootstrapping procedure (Preacher \& Hayes, 2008a, 2008b) was used to assess the role of time structure, social contact, collective purpose and financial strain in mediating the relationship between duration of sickness absence and depression. Results are presented in Table 4 (indirect effects) and Table 5 (contrasts). Figure 1 provides a graphical summary of the multiple mediator model.

The model as a whole was significant, $F(5,106)=33.46, p<0.001$, accounting for $61.22 \%$ of the variance in SDS scores. The total indirect effect was significant, 


\section{TABLE 3}

Bivariate correlations between LAMB scores and duration of sickness absence

\begin{tabular}{lc}
\hline LAMB Subscale & $\begin{array}{r}\text { Correlation with Duration of } \\
\text { sickness absence }(r)\end{array}$ \\
\hline Time Structure & $-.28^{* *}$ \\
Social Contact & $-.24^{* *}$ \\
Collective Purpose & $-.28^{* *}$ \\
Enforced Activity & -.15 \\
Status & -.12 \\
Financial Strain & $-.34^{* * *}$ \\
\hline
\end{tabular}

$* * p<.01{ }^{* * *} p<.001$

\section{TABLE 4}

Mediation of the effect of duration of sickness absence on severity of depressive symptoms through the latent and manifest benefits of employment: indirect effects

\begin{tabular}{|c|c|c|c|c|c|}
\hline & \multirow[b]{2}{*}{ Point Estimate } & \multicolumn{2}{|c|}{$\begin{array}{l}\text { Product of } \\
\text { Coefficients }\end{array}$} & \multicolumn{2}{|c|}{$\begin{array}{l}\text { Bootstrapping } \\
\text { BCa } 95 \% \mathrm{Cl}\end{array}$} \\
\hline & & $S E$ & $z$ & Lower & Upper \\
\hline Time Structure & .22 & .21 & 1.07 & -.15 & .76 \\
\hline Social Contact & .42 & .21 & $2.03^{*}$ & .07 & .96 \\
\hline Collective Purpose & .30 & .19 & 1.59 & -.07 & .99 \\
\hline Financial Strain & 1.07 & .35 & $3.07^{* *}$ & .51 & 1.77 \\
\hline TOTAL & 2.02 & .55 & $3.65^{* *}$ & .79 & 3.17 \\
\hline
\end{tabular}

indicating that the three latent and one manifest benefits of employment collectively mediated the relationship between duration of sickness absence and SDS scores. The significant total effect of duration of sickness absence on SDS scores (c path) became non-significant after accounting for the effects of the mediators (c' path) indicating full mediation of the relationship between duration of sickness absence and SDS scores. Social contact and financial strain each made a significant unique contribution toward mediation. Contrast analyses indicated that the specific indirect effect of financial strain was significantly greater than that of every other proposed mediator. Significant contrasts are presented in Table 5.

Post-hoc analyses were conducted to assess the strength of association between LAMB subscale and SDS scores for each group (sickness absent and partial fitness/modified duties) using Pearson correlation analyses (see Table 6). As shown in Table 6, all correlations were significant for both the sickness absent and modified duties groups. 


\section{TABLE 5}

Mediation of the effect of duration of sickness absence on severity of depressive symptoms through the latent and manifest benefits of employment: contrasts

\begin{tabular}{|c|c|c|c|c|c|}
\hline & \multirow[b]{2}{*}{ Point Estimate } & \multicolumn{2}{|c|}{$\begin{array}{l}\text { Product of } \\
\text { Coefficients }\end{array}$} & \multicolumn{2}{|c|}{$\begin{array}{l}\text { Bootstrapping } \\
\mathrm{BCa} 95 \% \mathrm{Cl}\end{array}$} \\
\hline & & $S E$ & $Z$ & Lower & Upper \\
\hline $\begin{array}{l}\text { Time Structure } \rightarrow \\
\text { Financial Strain }\end{array}$ & -.85 & .39 & $-2.15^{*}$ & -1.71 & -.11 \\
\hline $\begin{array}{l}\text { Social Contact } \rightarrow \\
\quad \text { Financial Strain }\end{array}$ & -.68 & .36 & $-1.90^{*}$ & -.1 .38 & -.05 \\
\hline $\begin{array}{l}\text { Collective Purpose } \rightarrow \\
\quad \text { Financial Strain }\end{array}$ & -.71 & .34 & $-2.08^{*}$ & -1.44 & .05 \\
\hline $\begin{array}{l}\text { Enforced Activity } \rightarrow \\
\quad \text { Financial Strain }\end{array}$ & -.88 & .33 & $-2.67^{* *}$ & -1.56 & -.28 \\
\hline Status $\rightarrow$ Financial Strain & -1.00 & .34 & $-2.91 * *$ & -1.67 & -.45 \\
\hline
\end{tabular}

Note: $\mathrm{BCa}$, bias corrected and accelerated; 1,000 bootstrap samples. $* p<.05 . * * p .01$.

Figures in bold indicate $95 \% \mathrm{CI}$ that does not include zero (i.e., $p<.05$ ).

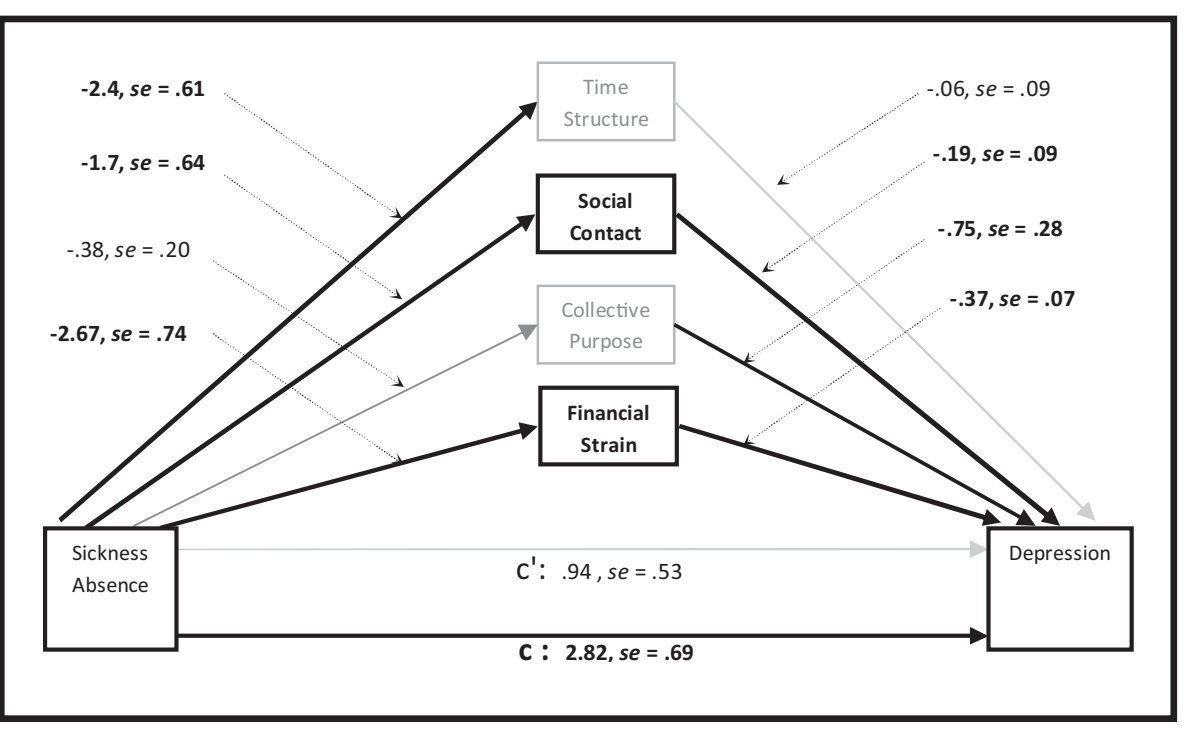

\section{FIGURE 1}

Mediation pathways between Duration of Sickness Absence and Depression (SDS total score) with point estimates and standard error (se). Significant pathways are in bold. Total effect of Duration of Sickness Absence on depression (c) is significant. Direct effect of Duration of Sickness Absence on Depression after accounting for mediators $\left(c^{\prime}\right)$ is not significant. Point estimate and standard error for indirect effects (ab), and bootstrapping estimates are reported in Table 3. 


\section{TABLE 6}

Bivariate correlations between LAMB scores and SDS by group

\begin{tabular}{lcc}
\hline & \multicolumn{2}{c}{ Correlation with SDS $(r)$} \\
\cline { 2 - 3 } & Sickness Absent Group & Modified Duties Group \\
\hline Time Structure & $-.48^{* * *}$ & $-.43^{* * *}$ \\
Social Contact & $-.57^{* * *}$ & $-.41^{* *}$ \\
Collective Purpose & $-.47^{* * *}$ & $-.69^{* * *}$ \\
Enforced Activity & $-.53^{* * *}$ & $-.53^{* * *}$ \\
Status & $-.50^{* * *}$ & $-.44^{* * *}$ \\
Financial Strain & $-.70^{* * *}$ & $-.60^{* * *}$ \\
\hline
\end{tabular}

$* * p<.01 . * * * p .001$.

A series of multiple regression analyses were conducted for each group to assess the relative contribution of each of the latent and manifest benefits of employment in predicting SDS scores. Preliminary analyses indicated no violation of the parametric assumptions for multiple regression.

A standard multiple regression was conducted for the sickness absent group, with the six LAMB subscales entered in a single block. The model as a whole was significant and explained $56.8 \%$ of the variance in $\operatorname{SDS}$ scores, $F(6,48)=12.81, p<0.001$. Financial strain was the only variable shown to make a significant unique contribution (beta $=0.50, p<0.001$ ) and uniquely accounted for $17.22 \%$ of SDS variance. A subsequent hierarchical multiple regression was conducted to assess the contribution to SDS variance of the latent benefits of employment (time structure, social contact, collective purpose, enforced activity, and status) after controlling for financial strain. Financial strain was entered at step 1, explaining $47 \%$ of SDS variance. Time structure, social contact, collective purpose, enforced activity and status were entered at step 2 explaining an additional $13.2 \%$ of SDS variance $\left(R^{2}\right.$ change $\left.=0.132\right)$.

For the modified duties group a standard multiple regression was conducted with the six LAMB subscales entered in a single block. The model as a whole was significant and explained $55.5 \%$ of total SDS variance, $F(6,50)=12.63, p<0.001$. Collective purpose and financial strain each made a significant unique contribution to SDS variance, with collective purpose recording a higher beta value (beta $=-0.45$, $p<0.001$ ) than financial strain (beta $=-0.29, p<0.05$ ). Collective purpose uniquely accounted for $12.67 \%$ of SDS variance while financial strain uniquely contributed $4.45 \%$.

Combined, the above results indicate that while a loss of the psychosocial benefits of employment contributed to depression in the non-working group, financial strain was the strongest predictor. However, in the group performing modified duties, the loss of 'collective purpose' was a stronger predictor of depression than was financial strain.

\section{Discussion}

This study's predictions that the prevalence of depression in a work disabled sample would exceed population averages, and that symptom severity would be positively 
correlated with duration of sickness absence, were supported. Thirty-six per cent of participants reported depression symptoms in the clinical range. This is nine times the Australian 12 month prevalence rate for depression (Australian Bureau of Statistics, 2007), but consistent with previous research showing a higher than average rate of depression among injured workers (Cohen et al., 2000; Dersh et al., 2002; Hush, 2008). Moreover, participants who were sickness absent were almost twice as likely to report clinical range depressive symptoms than those who were performing modified duties. Indeed, nearly half of the sickness absent group (47\%) returned SDS scores within the clinical range. Furthermore, there was a significant positive correlation between duration of sickness absence and the severity of reported depression symptoms; specifically, SDS total scores increased with time away from work, as did the likelihood of reporting clinical range depressive symptoms.

This study's second prediction, that financial strain (the manifest benefit of employment) and loss of the psychosocial (or latent) benefits of work would mediate the relationship between duration of sickness absence and depression, was also supported. Prior to conducting the mediation analysis, bivariate correlations between the benefits of work (the LAMB subscales), and (a) level of depression symptoms (the SDS scores), and (b) duration of sickness absence scores, were generated. As expected, all LAMB subscale scores showed a large negative correlation with the SDS scores, indicating that as the manifest and latent benefits of employment increased, depressive symptoms decreased. However, only four subscales (financial strain, time structure, social contact and collective purpose) were significantly associated with duration of sickness absence. This finding indicates that in the current sample at least, being away from work led to the loss of time structure, social contact and collective purpose, but not a loss of status or enforced activity. These results make sense in the context of the participants being off work due to illness, rather than being unemployed per se.

In Western society, when illness prevents work participation, employment status is exchanged for that of 'the sick role' (Parsons, 1951). This new status affords a person the right of exemption from normal duties and responsibilities, and the entitlement to special attention and support (which includes wage-replacement benefits). Thus, 'meaningful role in society' - which is measured by the LAMB status subscale - is likely maintained via this new role. The sick role also involves mutual responsibility, in that the ill person has a duty to attempt to get well. By engaging in activities to promote recovery and work resumption, an injured worker is 'fulfilling the (sick) role expectations' and thus addressing the LAMB enforced activity subscale criteria (Becker, 1974). Therefore, in this sample where all participants were injured workers involved with an occupational rehabilitation provider, it is not surprising to find they were not 'deprived' of status and enforced activity as latent benefits of employment.

Financial strain, the manifest benefit of employment, was found to contribute the strongest unique mediating effect in the relationship between duration of sickness absence and depression, and was the only variable to significantly predict depression in the sickness absence group. A large percentage $(71 \%)$ of this group had been off work for more than six months, which - in Australia - results in significantly reduced income to a level commensurate with unemployment benefits. Thus, the finding of the relationship between financial strain and depression in this group is consistent with the 'agency restriction' model, which posits that financial hardship associated 
with being unemployed is the key cause of psychological distress in this population (Fryer, 1986; Fryer \& McKenna, 1987; Whelan, 1992). A different picture emerged, however, in relation to the modified duties group.

In addition to financial strain, this study found that latent benefits of work also mediate between sickness absence and depression, with social contact making a unique contribution. Additionally, collective purpose was found to be the strongest predictor of depression in the modified duties group. These findings are consistent with the 'latent deprivation model' and suggest that beyond impaired financial circumstances (which can occur when full duties and usual over-time work is not performed) reduced social interactions (i.e., loss of contact or participation in shared goals) are key mechanisms by which separation from work contributes to psychological distress in injured workers. This finding is consistent with the results of qualitative research which has found that ongoing social contact with the workplace, and support from co-workers, is 'essential ... for . .. successful return to work' (Sager \& James, 2005, p. 133; MacEachen et al., 2007; Tjulin, MacEachen, \& Ekberg, 2010).

\section{Implications for Rehabilitation Practice}

The findings of this study attest to the prevalence of depression in physically injured workers and support current injury management procedures that aim to keep the worker connected to the workplace through early contact and the provision of modified duties. The findings suggest that the mechanism of efficacy of these strategies is the maintenance of the manifest and latent benefits of employment, which protect an injured worker against the development of secondary psychological distress. However, as evidenced in our sample, these procedures as currently implemented are not successful for all injured workers. Indeed, recent research has found that there is sometimes an awkward fit between expectations and actions (Tjulin et al., 2011), resulting in little or no contact with the absent injured worker and the failure to provide modified duties. Our findings suggest a possible new role for early intervention by rehabilitation counselors: to bridge the communication gap between injured workers and workplaces and prevent secondary losses and further disability. Thus, rather than making referrals when problems become chronic, workplace rehabilitation coordinators might consider referral to a rehabilitation counsellor as soon as a breach in workplace social relationships is detected.

\section{Limitations of the study}

Some limitations of this study should be noted. The cross-sectional design and use of correlational data mean that while a temporal relationship between duration of work absence and depression was assumed, this was not demonstrated in this study. Additionally, the response rate is unknown leading to questions about sampling bias and the representativeness of the sample. Further, as the research was conducted in one jurisdiction only, caution needs to be exercised when generalising the findings to the total population of injured workers. That said, the findings are explained by existing theory and are consistent with other empirical results. 


\section{Conclusion}

The findings of this study indicate that financial strain and the loss of the psychosocial benefits of work mediate the relationship between duration of sickness absence and depression in physically injured workers. Injury management procedures that promote early contact and the provision of modified work appear to have merit for continuing work participation. Return to work interventions should seek to enable resources for work re-engagement by injured workers.

\section{References}

AFOEM, \& RACP. (2011). The health benefits of work. Australiasian Faculty of Occupational and Environmental Medicine. Retrieved from http://www. healthbenefitsofwork.com.au

Australian Bureau of Statistics. (2007). National survey of mental health and well-being, Australia. Retrieved from http://www.abs.gov.au/ausstats/abs@.nsf/ latestproducts/4326

Australian Government. (2008). National mental health and disability employment strategy update. Setting the direction. Canberra, ACT: Commonwealth of Australia. Retrieved from http://www.daru.org.au/publications/items/2009/01/256000-upload-00001.pdf

Australian Safety and Compensation Council. (2009). The cost of work-related injury and illness for Australian employers, workers and the community: 2005-06. Retrieved from http://www.safeworkaustralia.gov.au/NR/rdonlyres/EAD5247E-98E7-4750-A35EA6BC9B1E7781/0/CostsofWorkRelatedInjuryAndDisease_Mar2009.pdf

Baril, R., Clarke, J., Friesen, M., Stock, S., \& Cole, D. (2003). Management of return-to-work programs for workers with musculoskeletal disorders: a qualitative study in three Canadian provinces. Social Science $\mathcal{E}$ Medicine, 57(11), 2101-2114. doi: 10.1016/s0277-9536(03)00131-x

Batinic, B., Selenko, E., Stiglbauer, B., \& Paul, K. (2010). Are workers in high-status jobs healthier than others? Assessing Jahoda's latent benefits of employment in two working populations. Work Eु Stress, 24(1), 73-87. doi: 10.1080/02678371003703859

Beardwood, B., Kirsh, B., \& Clark, J. (2005). Victims twice over: perceptions and experiences of injured workers. Qualitative Health Research, 15(1), 30-48. doi: 10.1177/1049732304268716

Beck, A., Ward, C., Mendelson, M., Mock, J., \& Erraugh, J. (1961). An inventory for measuring depression. Archives of General Psychiatry, 4, 53-63.

Becker, M. (1974). The health belief model and sick role behavior. Health Education Monographs, 2, 409-419.

Biggs, J., Wylie, L., \& Ziegler, V. (1978). Validity of the Zung self-rating depression scale. British Journal of Psychiatry, 132, 381-385. doi: 10.1192/bjp.132.4.381

Bültmann, U., Franche, R., Hogg-Johnson, S., Côté, P., Lee, H., Severin, C., ... Carnide, N. (2007). Health status, work limitations, and return-to-work trajectories in injured workers with musculoskeletal disorders. Quality of Life Research, 16, 1167-1178. doi: 10.1007/s11136-0079229-x

Butcher, J.N., Dahlstrom, W.G., Graham, J.R., Tellegen, A., \& Kaemmer, B. (1989). MMPI-2: Minnesota Multiphasic Personality Inventory - 2: Manual for administration and scoring. Minneapolis: University of Minnesota Press.

Cohen, M., Nicholas, M., \& Blanch, A. (2000). Medical assessment and management of workrelated low back or neck/arm pain. Journal of Occupational Health and Safety, 16(4), 307317.

Creed, P., \& Klisch, J. (2005). Future outlook and financial strain: Testing the personal agency and latent deprivation models of unemployment and well-being. Journal of Occupational Health Psychology, 10, 251-260. doi: 10.1037/1076-8998.10.3.251 
Creed, P., \& Macintyre, S. (2001). The relative effects of deprivation of the latent and manifest benefits of employment on the well-being of unemployed people. Journal of Occupational Health Psychology, 6(4), 324-331. doi: 10.1348/096317999166518

De Jonghe, J., \& Baneke, J. (1989). The Zung Self-Rating Depression Scale: A replication study on reliability, validity and prediction. Psychological Reports, 64, 833-834.

Dersh, J., Gatchel, R., Polatin, P., \& Mayer, T. (2002). Prevalence of psychiatric disorders in patients with chronic work-related musculoskeletal pain disability. Journal of Occupational and Environmental Medicine, 44, 459-468. doi: 10.1097/00043764-200205000-00014

Dunstan, D.A. (2009). Are sickness certificates doing our patients harm? Australian Family Physician, $38(1-2), 61-63$.

Eysenck, H.J., \& Eysenck, S.B.G. (1996). Manual of the Eysenck Personality Scales (EPS-Adult). London: Hodder \& Stoughton Educational.

Fishbain, D., Cutler, R., Rosomoff, H., \& Rosomoff, R. (1997). Chronic pain-associated depression: antecedent or consequence of chronic pain? A review. The Clinical Journal of Pain, 13(2), 116137.

Franche, R., Cullen, K., Clarke, J., Irvin, E., Sinclair, S., Frank, J., \& the Institute for Work and Health Workplace-Based, R. T. W. Intervention Literature Review Research Team (2005). Workplacebased return-to-work interventions: a systematic review of the quantitative literature. Journal of Occupational Rehabilitation, 15(4), 607-631. doi: 10.1007/s10926-005-8038-8

Frank, J., Sinclair, S., Hogg-Johnson, S., Shannon, H., Bombardier, C., Beaton, D., \& Cole, D. (1998). Preventing disability from work-related low-back pain: new evidence gives new hope - if we can just get all the players onside. Canadian Medical Association Journal, 158(12), 1625-1631.

Fryer, D. (1986). Employment deprivation and personal agency during unemployment. Social Behaviour, 1, 3-23.

Fryer, D.M. (1995). Labour market disadvantage, deprivation and mental health benefit agency. The Psychologist, 6, 265-272.

Fryer, D. (2002). Unemployment and mental health: hazards and challenges of psychology in the community. In K. Isaksson, C. Hogstedt, C. Eriksson, \& T. Theorell (Eds.), Health Effects of the New Labour Market (pp. 11-23). New York: Kluwer Academic.

Fryer, D., \& McKenna, S. (1987). The laying off of hands: Unemployment and the experience of time. In S. Fineman (Ed.), Unemployment: Personal and social consequences (pp. 47-73). London: Tavistock.

Gabrys, J., \& Peters, K. (1985). Reliability, discriminant and predictive validity of the Zung SelfRating Depression Scale. Psychological Reports, 57, 1091-1096.

Gamborg, B., Elliott, W., \& Curtis, K. (1992). Chronic disability syndrome. Canadian Family Physician, 37, 1966-1073.

Goldberg, D.P. (1972). The Detection of Psychiatric Illness by Questionnaire. London: Oxford University Press.

Hamilton, M. (1960). A rating scale for depression. Journal of Neurology, Neurosurgery and Psychiatry, $23,56-62$.

Hathaway, S., \& McKinley, J. (1942). A multiphasic personality schedule (Minnesota): III. The measurement of symptomatic depression. Journal of Psychology, 14, 73-84.

Health and Safety Executive (2010). Health and Safety Statistics: Self-reported work-related illness and workplace injuries in 2009/10. Suffolk, UK: Retrieved from http://www .hse.gov.uk/statistics/swi/index.htm

Hush, J. (2008). Clinical management of occupational low back pain in Australia: What is the real picture? Journal of Occupational Rehabilitation, 18, 375-380. doi: 10.1007/ s10926-008-9149-9

Jackson, T. (1999). Differences in psychological experience of employed, unemployed and student samples of young adults. Journal of Psychology, 133, 49-60. 
Jahoda, M. (1982). Employment and Unemployment: A socio-psychological analysis. Cambridge: Cambridge University Press.

Kuoppala, J., \& Lamminpää, A. (2008). Rehabilitation and work ability: A systematic literature review. Journal of Rehabilitation Medicine, 40(10), 796-804. doi: 10.2340/16501977-0270

McKee-Ryan, F., Song, Z., Wanberg, C.R., \& Kinicki, A.J. (2005). Psychological and physical wellbeing during unemployment: A meta-analytic study. Journal of Applied Psychology, 90(1), 53-76. doi:10.1037/0021-9010.90.1.53

MacEachen, E., Ferrier, S., Kosny, A., \& Chambers, L. (2007). A deliberation on 'hurt versus harm' logic in early-return-to-work policy. Policy and Practice in Health and Safety, 5, 41-62.

MacEachen, E., Kosny, A., Ferrier, S., \& Chambers, L. (2010). The "toxic dose" of system problems: Why some injured workers don't return to work as expected. Journal of Occupational Rehabilitation, 20, 349-366.

Mallinckrodt, B., Abraham, W.T., Wei, M., \& Russell, D.W. (2006). Advances in testing the statistical significance of mediation effects. Journal of Counseling Psychology, 53, 372-378. doi: 10.1037/0022-0167.53.3.372

Muller, J., Creed, P., Waters, L., \& Machin, M. (2005). The development and preliminary testing of a scale to measure the latent and manifest benefits of employment. European Journal of Psychological Assessment, 21, 191-198. doi: 10.1027/1015-5759.21.3.191

New York State Workers Compensation Board. (2009). Return to work policy. Retrieved 10 March 2012, from http://www.wcb.ny.gov/content/main/SubjectNos/sn046_ 309. jsp

Nicholas, M. (2002). Reducing disability in injured workers: the importance of collaborative management. In S.J. Linton (Ed.), New Avenues for the Prevention of Chronic Musculoskeletal Pain and Disability. Pain research and clinical management (Vol. 12, pp. 33-46): Elsevier Science B.V.

ParsonsT. (Ed.). (1951). The Social Systems. New York: Free Press.

Pincus, T., Burton, A.K., Vogel, S., \& Field, A.P. (2002). A systematic review of psychological factors as predictors of chronicity/disability in prospective cohorts of low back pain. Spine, 27(5), E109-E120.

Preacher, K., \& Hayes, A. (2008a). Asymptotic and resampling strategies for assessing and comparing indirect effects in multiple mediator models. Behavior Research Methods, 40, 879-891. doi: 10.3758/BRM.40.3.879

Preacher, K., \& Hayes, A. (2008b). SPSS macro for multiple mediation. Retrieved from http://www.comm.ohio-state.edu/ahayes/

Price, R., Choi, J., \& Vinokur, A. (2002). Links in the chain of adversity following job loss: How financial strain and loss of personal control lead to depression, impaired functioning, and poor health. Journal of Occupational Health Psychology, 7(4), 302-312. doi: 10.1037/0033-2909.107.2.238

Sager, L., \& James, C. (2005). Injured workers' perspectives of their rehabilitation process under the New South Wales Workers Compensation System. Australian Occupational Therapy Journal, 52, 127-135.

Schaeffer, A., Brown, J., Watson, C. G., Plemel, D., DeMotts, J., Howard, M., ... Ballewang, B. (1985). Comparison of the validities of the Beck, Zung and MMPI Depression scales. Journal of Consulting and Clinical Psychology, 53, 415-418.

Shrout, P. E., \& Bolger, N. (2002). Mediation in experimental and non-experimental studies: New procedures and recommendations. Psychological Methods, 7, 422-445. doi: 10.1037//1082989X.7.4.422

Sobel, M. (1982). Asymptotic confidence intervals for indirect effects in structural equations models. In S. Leinhart (Ed.), Sociological Methodology 1982 (pp. 290-312). San Francisco: Jossey-Bass.

Sobel, M. (1986). Some new results on indirect effects and their standard errors in covariance structure models. In N. Tuma (Ed.), Social Methodology 1986 (pp. 159-186). Washington, DC: American Sociological Association. 
Stice, B., \& Dik, B. (2009). Depression among injured workers receiving vocational rehabilitation: Contributions of work values, pain, and stress. Journal of Occupational Rehabilitation, 19(4), 354 363. doi: 10.1007/s10926-009-9190-3

Sullivan, M., Adams, H., Tripp, D., \& Stanish, W. (2008). Stage of chronicity and treatment response in patients with musculoskeletal injuries and concurrent symptoms of depression. Pain, 135, 151-159. doi:10.1016/j.pain.2007.05.021

Szanton, S., Thorpe, R., \& Whitfield, K. (2010). Life-course financial strain and health in AfricanAmericans. Social Science $\mathcal{E}$ Medicine, 71(2), 259-265. doi: 10.1016/j. socscimed.2010.04.001

Thurber, S., Snow, M., \& Honts, C.R. (2002). The Zung Self-rating Depression Scale: Convergent validity and diagnostic discrimination. Assessment, 9, 401-405. doi: 10.1177/1073191102238471

Tjulin, A., MacEachen, E., \& Ekberg, K. (2010). Exploring workplace actors' experiences of the social organization of return-to-work. Journal of Occupational Rehabilitation, 20, 311-321.

Tjulin, A., MacEachen, E., \& Ekberg, K. (2011). Exploring the meaning of early contact in returnto-work from workplace actors' perspective. Disability and Rehabilitation, 33(2), 137-145. doi: 10.3109/09638288.2010.489630

Underlid, K. (1996). Activity during unemployment and mental health. Scandinavian Journal of Psychology, 37(3), 269-281. doi: 10.1111/j.1467-9450.1996.tb00659.x

Wanberg, C., Griffiths, R., \& Gavin, M. (1997). Time structure and unemployment: A longitudinal investigation. Journal of Occupational and Organizational Psychology, 70(1), 75-95. doi: 10.1111/j.2044-8325.1997.tb00632.x

Waters, L., \& Moore, K. (2002). Reducing latent deprivation during unemployment: The role of meaningful activity. Journal of Occupational and Organizational Psychology, 75(1), 15-32. doi: 10.1037/0033-2909.103.3.411

Watson, P. (2001). From back pain to work: A collaborative initiative between the National Disability Development initiative and the Department of Behavioural Medicine Salford Royal Hospitals Trust. Manchester, UK: Salford Royal Hospitals NHS Trust.

Whelan, C. (1992). The role of income, life style deprivation and financial strain in mediating the impact of unemployment on psychological distress: Evidence from the Republic of Ireland. Journal of Occupational and Organizational Psychology, 65, 331-344.

Winefield, A., Montgomery, B., Gault, U., Muller, J., O'Gorman, J., Reser, J., \& Roland, D. (2002). The psychology of work and unemployment in Australia today: An Australian Psychological Society discussion paper. Australian Psychologist, 37(1), 1-9. doi: 10.1080/00050060210001706606

WorkCover Authority of NSW. (2010a). Injury management. Retrieved 10 March 2012, from http://www.workcover.nsw.gov.au/injuriesclaims/injurymanagement/Pages/default. aspx

WorkCover Authority of NSW. (2010b). New South Wales workers compensation statistical bulletin 2008/2009. Sydney, Australia: Knowledge Management Branch, WorkCover NSW.

WorkCover Authority of NSW. (2011). Benefits and entitlements. Retrieved 2 June 2012, from http://www.workcover.nsw.gov.au/injuriesclaims/benefitsentitlements/Pages/ default.aspx

Workplace Safety and Insurance Board. (2011). Return to work. Retrieved 22 December 2011, from http://www.wsib.on.ca/en/community/WSIB/230/ArticleDetail/24338?vgnextoid $=7466 \mathrm{e} 35 \mathrm{c} 819 \mathrm{~d} 7210 \mathrm{VgnVCM} 100000449 \mathrm{c} 710 \mathrm{aRCRD} \&$ vgnextchannel $=91 \mathrm{~d} 20 \mathrm{~b} 368 \mathrm{~d} 5 \mathrm{dd} 110 \mathrm{~V}$ gnVCM1000000e18120aRCRD

World Health Organization. (2003). The burden of musculoskeletal conditions at the start of the new millenium. In WHO Technical Report Series 919. Geneva: WHO.

Zung, W. (1965). A self-rating depression scale. Archives of General Psychiatry, 12, 63-70. 